\title{
PERIODIC PULSE PLATING OF MID-ASPECT RATIO PRINTED CIRCUIT BOARDS FOR ENHANCED PRODUCTIVITY
}

\author{
Carmichael Gugliotti, Rich Bellemare, Andy Oh, Ron Blake \\ MacDermid Alpha Electronics Solutions \\ Waterbury, CT, USA
}

\begin{abstract}
Pulse plating of copper has typically found use in the plating of very difficult, high aspect ratio printed circuit boards. Its ability to provide throwing power deep within through holes with aspect ratios as high as 30:1 is well established. This technology has long been thought of as a high technology, high cost, specialty process applicable only to high end products. This paper will discuss the advantages that pulse plating offers over conventional DC copper plating in high volume production applications for panels with aspect ratios of up to $12: 1$. These advantages are reduced plating time, increased throughput, and reduced plated copper thickness on the panel surface while meeting minimum in-hole copper thickness requirements.
\end{abstract}

Key words: Pulse Plating, Copper Plating, Mid-Aspect Ratio.

\section{INTRODUCTION}

Pulse plating of copper has typically found use in the plating of very difficult, high aspect ratio printed circuit boards. Its ability to provide throwing power deep within through holes with aspect ratios as high as 30:1 is well established. This technology has long been thought of as a high technology, high cost, specialty process applicable only to high end products [1]. With the continued miniaturization of electronic components and the increased functionality of electronic devices, even simple technology circuit boards have become thicker and more complex. This has pushed the capabilities of conventional DC copper systems to their limits causing bottlenecks in throughput due to the excessive plating times required for thicker boards while also limiting finer line capabilities due to over-plating of the surface with copper to meet minimum in-hole copper thickness requirements.

Research has continued to improve DC plating systems but has started to see smaller and smaller degrees of improvement in being able to plate copper evenly in the center of holes in the thicker boards as well as minimize surface copper. As DC plating reaches its limits and technology continues to advance, a need for an economically feasible plating system has become increasingly necessary. A potential market is developing for a mid-aspect ratio pulse plating bath that can perform better than the typical high throw DC copper baths without the high cost of a high-end pulse bath.

\section{BACKGROUND}

Originally, printed circuit board designs were simple. They were typically thin and had minimal detail work on the surface. Conventional DC copper baths could easily meet the plating requirements of these designs. Often panels plated with $70-80 \%$ efficiency were acceptable. As electronics technology has advanced, there have been significant changes to PCB architecture. These changes include densification of circuitry, higher functionality, and thicker panels allowing for more to be done in a smaller area [2]. A large part of this has been driven by technology changes in the mobile phone market leading to smaller and more advanced phones.

As advancements have occurred, chemical suppliers have continued to improve their DC plating systems to meet new plating requirements. New DC baths have provided significant improvements to throwing power and thickness distribution. Many high-volume board designs however have advanced beyond the capabilities of DC plating technology due to the inability to meet throwing power requirements, leading to an over-plated surface, long plating time, and a significant waste of copper. The over-plated surface must be etched, increasing processing time and wasting copper. The over-plated surface also limits HDI (high density interconnects) designs due to lateral undercutting of the lines resulting in poor quality traces.

Pulse plating technology offers a substantial increase in performance over DC plating. Pulse plating is able to plate copper into deeper through holes and maintain an even plating thickness throughout the hole. It is also able to minimize surface copper by plating at a higher efficiency in the hole which results in savings both on anode costs and on etching. Pulse plating can maintain a 1:1 plating thickness ratio between the hole and surface allowing for a more precise thickness control and can operate at higher current densities. Current densities can be run higher than 30ASF and still give good results. The reduced surface copper makes it easier to final copper etch and more compatible with HDI designs.

Pulse plating technology has been used in plating copper for printed circuit boards for decades. The main drawback of pulse plating has been the high costs of the pulse rectifiers and the chemical additives. While pulse plating systems have typically been used for high aspect ratio circuit boards with difficult designs, they can also be modified to meet the requirements within the mid-aspect ratio segment. With the availability of lower cost pulse rectifiers, 
pulse plating systems can be designed to provide the good throwing power and high throughput at economical operating costs that are specifically required for the mid-aspect ratio market segment. Currently, a 600amp DC rectifier might cost approximately $\$ 7,000$ US while a typical pulse rectifier of the same capacity might cost approximately $\$ 13,000$ US.

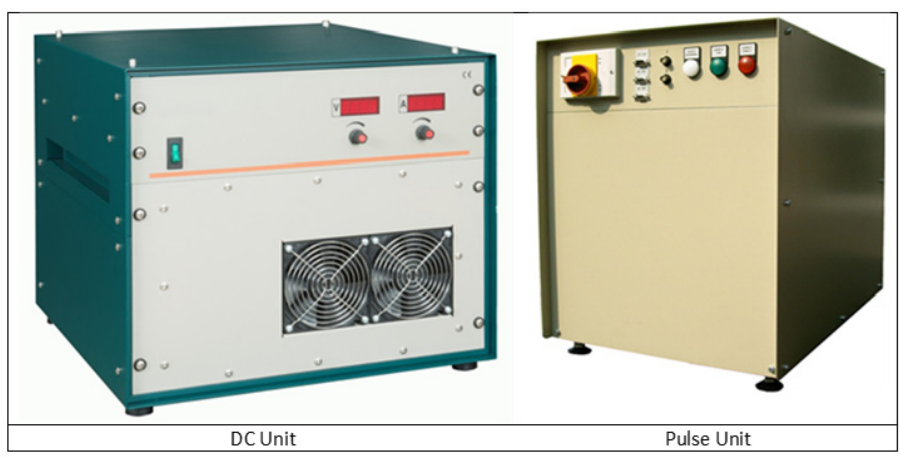

Figure 1. DC vs Pulse Rectifiers

This new pulse system must meet the performance requirements of high volume, mid-aspect ratio, HDI designs. The key factors to a successful system would be to maintain good throwing power, high throughput, minimal copper over plate, less copper etching, HDI capability, and simple pulse waveforms.

\section{PLATING}

Conventional DC or direct current acid copper plating is a wellestablished process entailing the use of cathodic current supplied by a DC rectifier to deposit a copper layer with good physical properties onto a circuit board from a plating solution containing copper sulfate, sulfuric acid, chloride ions, and a variety of additives that control the deposition process. These additives typically include a wetter, brightener, and a leveler.

\section{Wetter}

The wetter, typically a high molecular weight polyglycol, acts as a plating suppressor. When a direct current is applied, the wetter, in conjunction with the chloride, forms a semi-insulating blanket over the PCB surface which inhibits the migration of copper ions to the surface and controls the reduction of copper ions at the surface. This controlled initiation and grain growth of the copper deposit results in a smoother, more even coating.

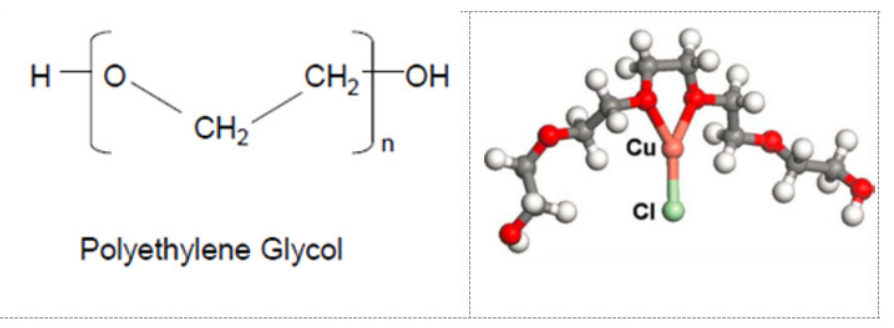

Figure 2. Sample Wetter Molecule

\section{Brightener}

The brightener, typically a low molecular weight sulfur compound, acts as an accelerator by forming low activation energy bridges to the copper surface. The brightener tends to increase the rate of formation of nucleation sites for copper grain growth and speed up the deposition rate. The result is a finer grained deposit with greater brightness.

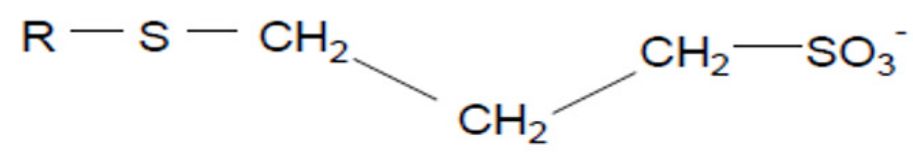

\section{Brightener compounds}

\section{Figure 3. Sample Brightener Molecule}

\section{Leveler}

The leveler acts as a secondary plating suppressor that slows the deposition rate on peaks at a microscopic scale to provide a further leveling of the deposit to produce a mirror like finish.

When current is applied in DC plating, an equilibrium is established in terms of additive adsorption, current density distribution, and plating rate. Though the additives, acting as deposition modifiers, redistribute current to a certain extent, the overall deposition is still governed by Faraday's Law. Outside surfaces and edges will accumulate higher charge densities and plate thicker than lower charge density areas such as internal recesses and internal hole walls of through holes.

\section{Drawbacks of DC Plating}

DC copper plating is limited by the efficiency at which it can plate into the hole as well as the evenness of the plating along the through hole walls. To compensate for this, PCB manufacturers have to over-plate the surface to meet the requirements inside the hole. The over-plated surface requires a greater amount of etching which increases time and cost in the process. Additionally, plating the extra copper requires more time thus reducing throughput along with the wasted cost of additional copper.

\section{PULSE PLATING}

In pulse plating, the solutions still contain typical components such as copper sulfate, sulfuric acid, chloride ions, and additives, but special rectification is used to vary the current using pulse waves throughout the plating cycle to disrupt the equilibrium formation of the additive films and redistribute current into low charge density areas. These pulse waves consist of a cathodic, or forward cycle, followed by a short, high current density anodic, or reverse cycle.

During the forward cycle, formation of the additive films and low energy bridges begins to occur as with DC plating. The high energy reverse pulse, which is distributed mainly around high charge density areas, then breaks the low energy brightener bridges in these areas while maintaining them in the low charge density areas (See Figure 4). With the next forward cycle, plating begins again 
in a non-equilibrium state which the system tries to re-form but is unable to maintain due to the following reverse cycle. The effect of this is that a relatively high plating rate is maintained within the low charge density areas such as inside the through holes as the brightener bridges are maintained, while greater suppression is kept in the higher charge density areas due to the breakage of these accelerating bridges.

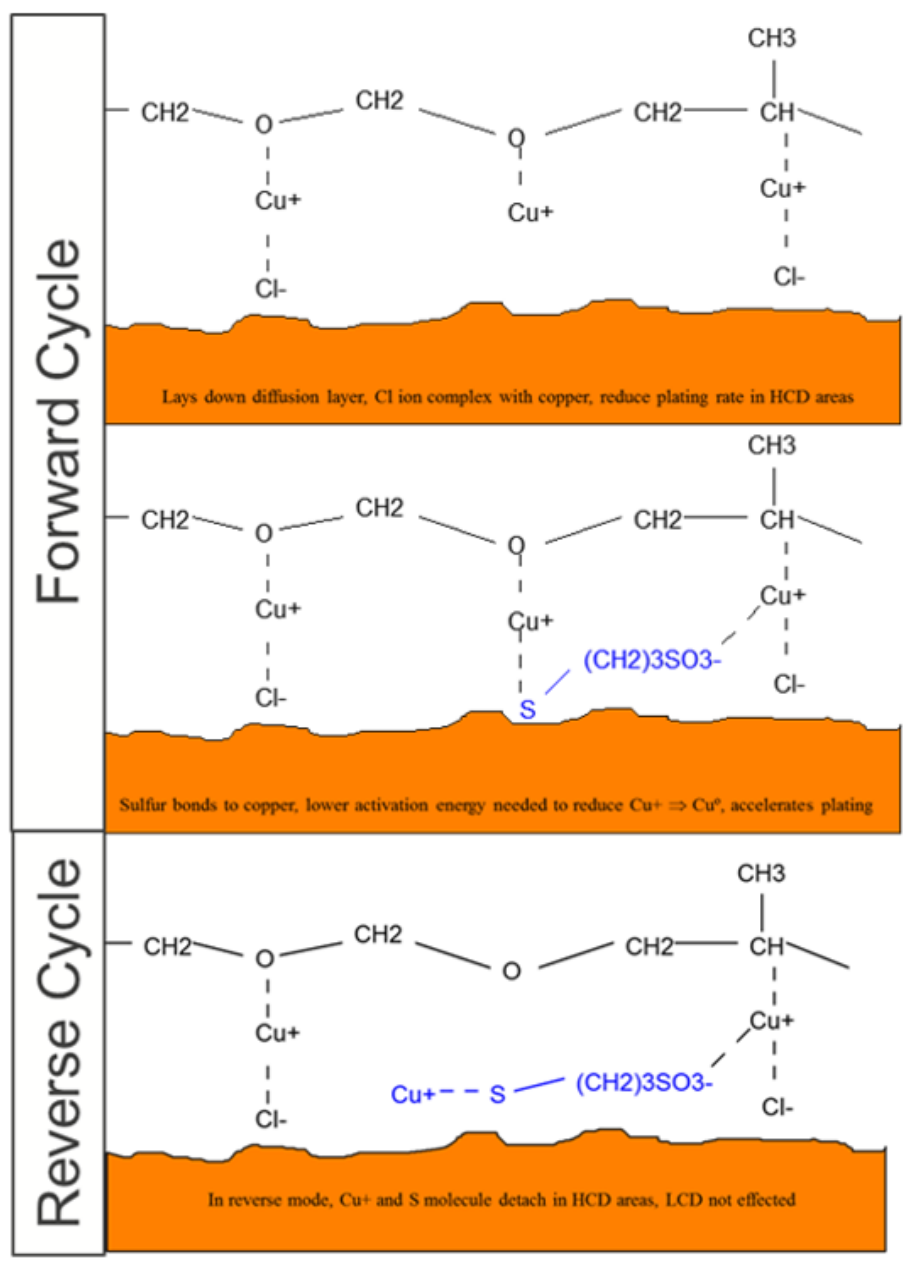

Figure 4. Pulse Cycle

There are a wide variety of pulse waves that can be used to modify current distribution and increase throwing power on a panel. These are typically expressed in terms of the ratio of forward to reverse time in milliseconds and forward to reverse current density in amps per square foot. Typical forward: reverse times are 100:5ms or $20: 1 \mathrm{~ms}$ with reverse currents of $1 \mathrm{x}, 2 \mathrm{x}$, or $3 \mathrm{x}$ the forward current. The higher the negative current, the more aggressive the pulse cycle and the more matte the surface will appear. A multi-step process can be used to slowly reduce the reverse current as plating continues to give a more even, shiny appearance on the finished board without sacrificing throwing power.

\section{Pulse Waves}

Pulse waves can be designed in a variety of ways. A simple periodic pulse wave introduces a gap where there is no flow of current to the bath before returning to the forward current. The introduction of a reverse current is considered a periodic pulse reverse (PPR) and can include a dead time with no current or just switch between forward and reverse current. For this experiment, simple PPR waves were used. It is possible to create complex pulse waves by changing factors such as the reverse current, the pulse time, or the base current of the wave. Complex waves are not required for mid-aspect circuit board designs but are outlined in Figure 5.
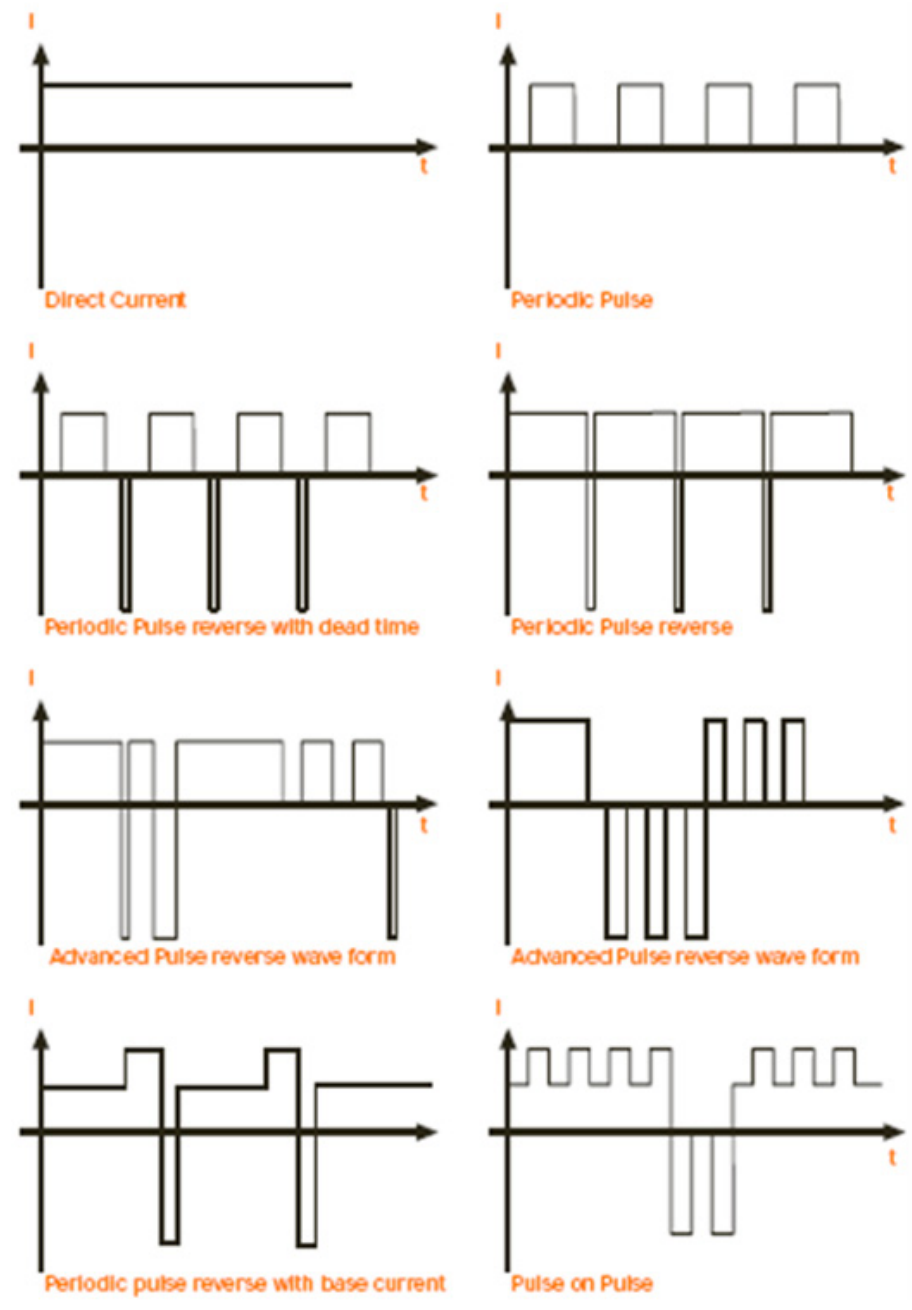

Figure 5. DC vs Pulse Cycles 


\section{EXPERIMENTAL}

\section{Experiment}

A comprehensive DOE was done to compare the differences in performance between DC plating and three pulse cycles in a system designed for mid-aspect ratio panels. Panels were evaluated for appearance, throwing power in the hole and at the knee, and reliability. The panels used were two thicknesses, $1.6 \mathrm{~mm}$ and $2.4 \mathrm{~mm}$ thick, with a variety of hole sizes to provide a variety of aspect ratios for evaluation (see Table 1).

Table 1. DOE Conditions

*Percentages indicate the percentage of the plating cycle time

\begin{tabular}{|c|c|c|c|}
\hline Cycle & $\begin{array}{c}\text { F/R Time Ratio } \\
(\mathrm{ms})\end{array}$ & R/F Current Ratio & $\begin{array}{c}\text { Forward Current Density } \\
\text { (ASF) }\end{array}$ \\
\hline DC & N/A & N/A & 30 \\
\hline $\begin{array}{c}\text { Single Step } \\
\text { (Lower Frequency) }\end{array}$ & $100 / 5$ & $2 \mathrm{X}$ & 30 \\
\hline $\begin{array}{c}\text { Single Step (Higher } \\
\text { Frequency) }\end{array}$ & $20 / 1$ & $2.5 \mathrm{X}$ & 30 \\
\hline Multistep & $20 / 1$ & $\begin{array}{c}3 \mathrm{X}-2 \mathrm{X}-1 \mathrm{X} \\
60 \%-20 \%-20 \% \%^{*}\end{array}$ & 30 \\
\hline
\end{tabular}

The primary attribute in pulse plating is throwing power, or the amount of copper plated in the hole compared to the copper plated on the surface. To maximize accuracy, each throwing power result was calculated from four measurements on the surface and two measurements in the hole as in Figure 6.

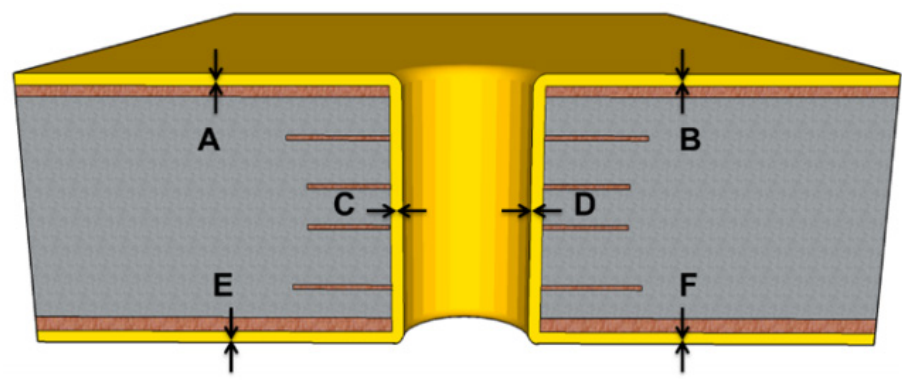

Figure 6. TP\% Measurement Locations

The two measurements, $\mathrm{C}$ and $\mathrm{D}$, in the hole were then averaged and divided by the average surface copper number, based on A, B, $\mathrm{E}$ and $\mathrm{F}$ measurements. The resulting number was then converted to a percentage for comparison for each test.

Throwing power was also evaluated at the knee of the hole. The throwing power at the knee was determined by taking the measurement at point B, from corner of the copper foil to the outside edge of the plated copper, and dividing by the thickness of the surface copper, A, multiplied by 100 (see Figure 7). Results were similar across all aspect ratios and panel thickness.

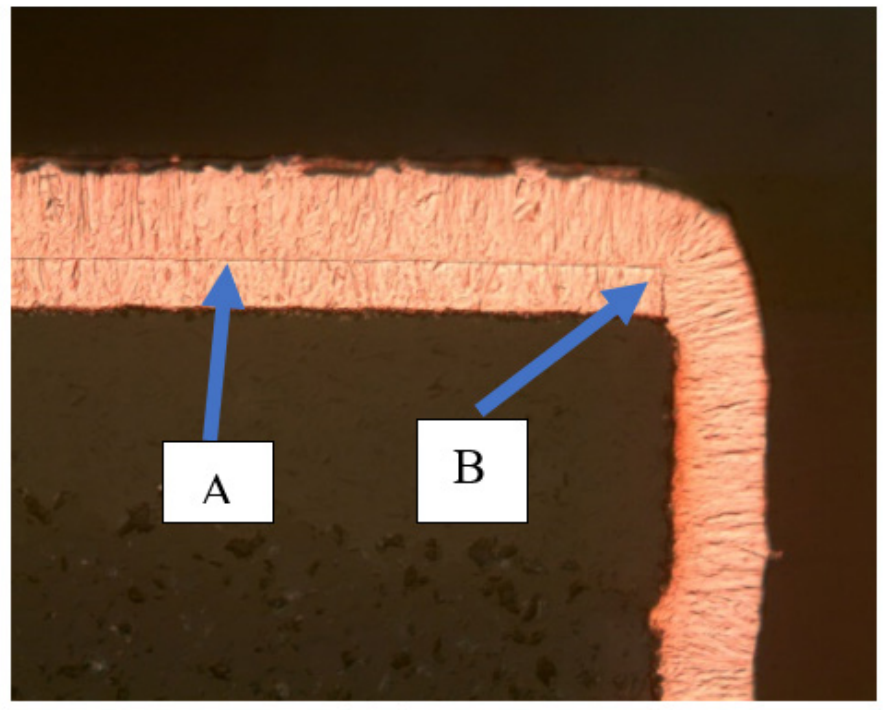

Figure 7. Knee thickness example

\section{RESULTS}

The results showed that pulse plating can be used to successfully plate boards of 1.6 to $2.4 \mathrm{~mm}$ thick with aspect ratios of $12: 1$ or less, while easily maintaining 100\% throwing power.

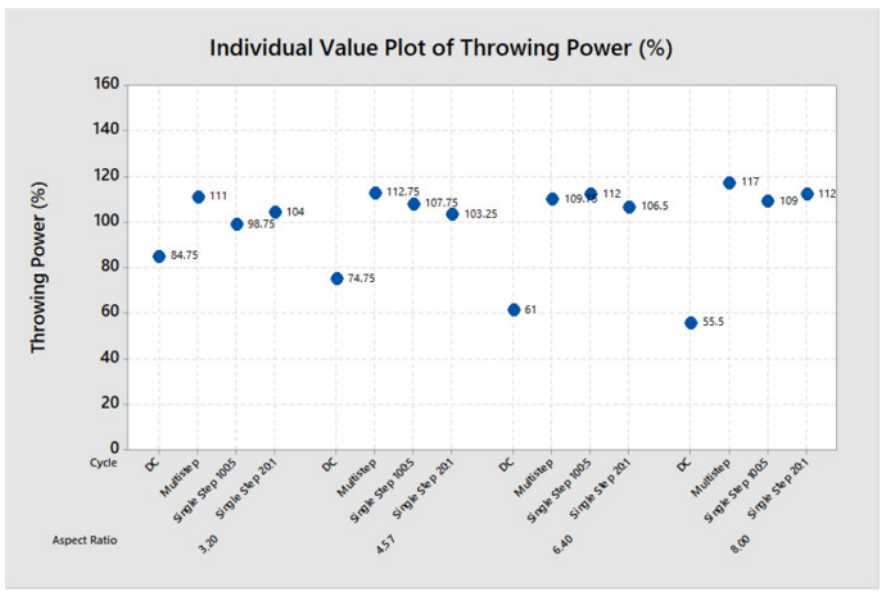

Figure 8. Throwing power on a $1.6 \mathrm{~mm}$ board at 30ASF

In Figure 8, results compare a typical DC process to the midaspect ratio pulse bath with three different pulse cycles at various aspect ratios. Each set of data shows DC, a multistep process, single step 100:5, and single step 20:1. The aspect ratios were 1.2:1, 4.5:1, $6.4: 1$, and 8:1. The results show the ease of maintaining $100 \%$ throwing power for the three pulse plated sets compared to the DC plated set which dropped considerably as the aspect ratio increased. The DC plating began at $85 \%$ for the lowest aspect ratio hole and dropped to $56 \%$ for the highest aspect ratio hole. 


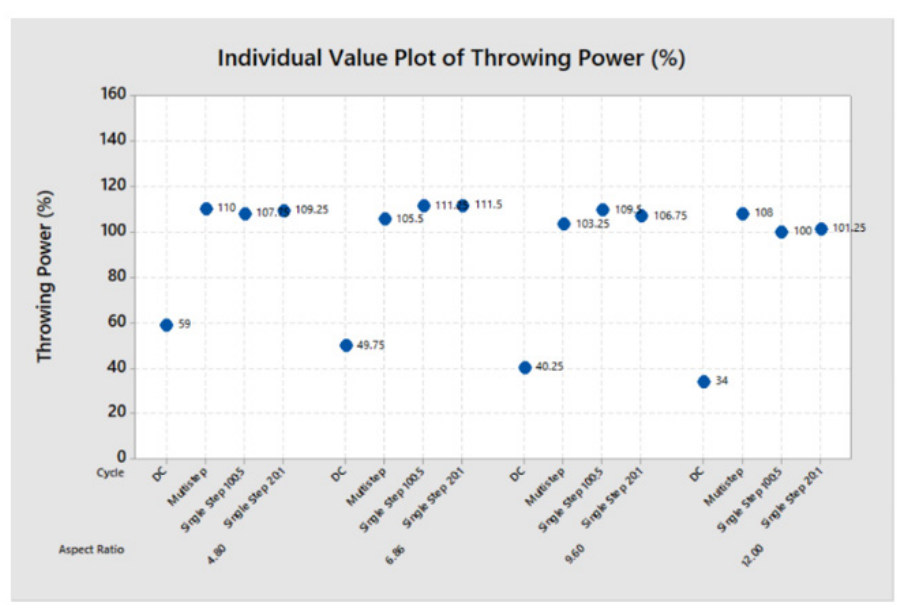

Figure 9. Throwing power on a $2.4 \mathrm{~mm}$ board at 30ASF

Figure 9 shows similar results to Figure 8 with a $2.4 \mathrm{~mm}$ thick panel. The $2.4 \mathrm{~mm}$ panel had higher aspect ratios of $4.8: 1,6: 1,9.6: 1$ and $12: 1$. In this case, the trend was clearer with the mid-aspect ratio pulse bath easily maintaining $100 \%$ or greater throwing power while the DC bath started significantly lower at 59\% and decreased to $34 \%$ at the higher aspect ratios.

Comparing the DC plating to the three pulse waves, there was no statistically significant difference in knee thickness with all cycles showing a knee thickness of $80-90 \%$ of the surface copper. It is important for the reliability of the through hole to have enough thickness of copper in this area. Thin knees can lead to cracking under thermal stress. A comparison of pulse plating vs. DC plating on mid-aspect ratio plated through holes can be seen in Figure 10.
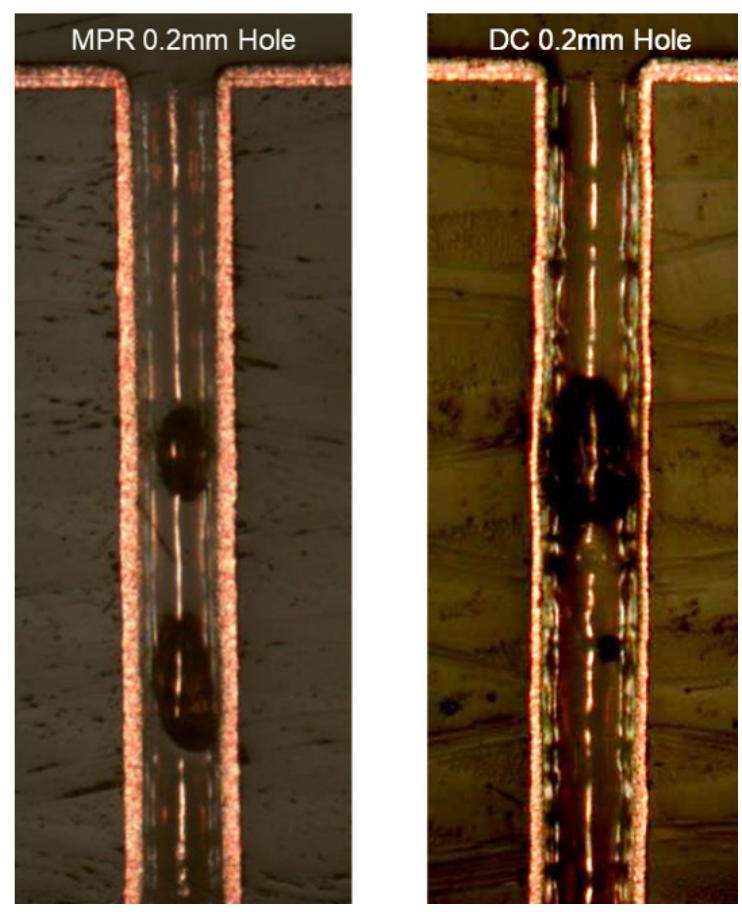

Figure 10. DC vs Pulse Plating on $0.2 \mathrm{~mm}$ hole
The main effects were evaluated for throwing power on the $1.6 \mathrm{~mm}$ and $2.4 \mathrm{~mm}$ thick panels (Figures 11 and 12). The largest effect on throwing power was the cycle used, with DC plating showing significantly lower performance than any of the pulse cycles. Bath age, from $25 \mathrm{Ah} / \mathrm{L}$ to $175 \mathrm{Ah} / \mathrm{L}$, was not significant based on the results. In the $1.6 \mathrm{~mm}$ panel the hole diameter and aspect ratio did not show a large effect across the aspect ratios tested. In thicker panels there is a trend where the larger the hole diameter, the better the performance and the lower the aspect ratio the better the performance. This was based on the large contribution of the DC plated panels in the DOE due to the poor performance as aspect ratio increased and hole diameter decreased. Removing the DC results, there was no significant effect for the aspect ratios or hole diameter on throwing power.

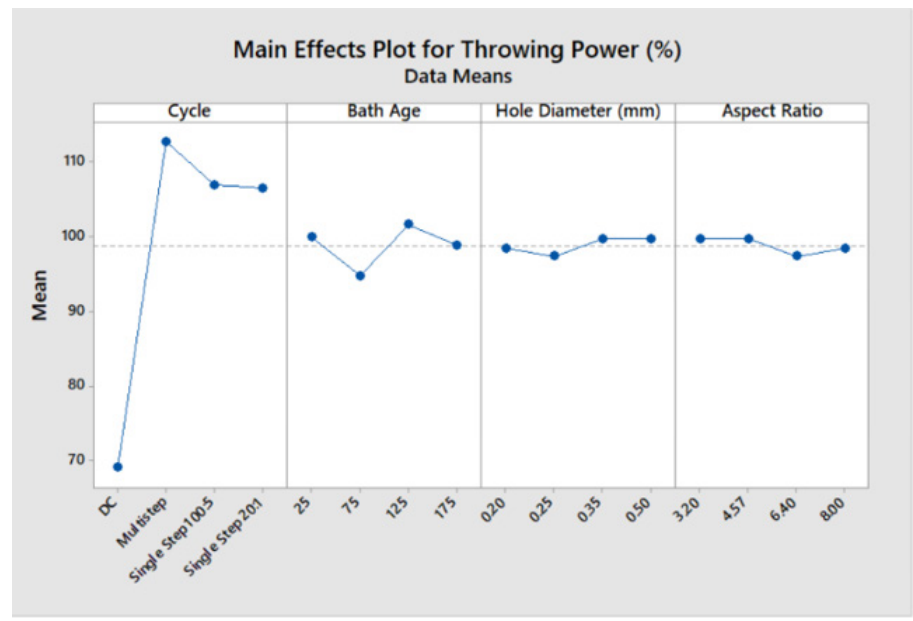

Figure 11. Minitab Main Effects Plot for $1.6 \mathrm{~mm}$ Panels

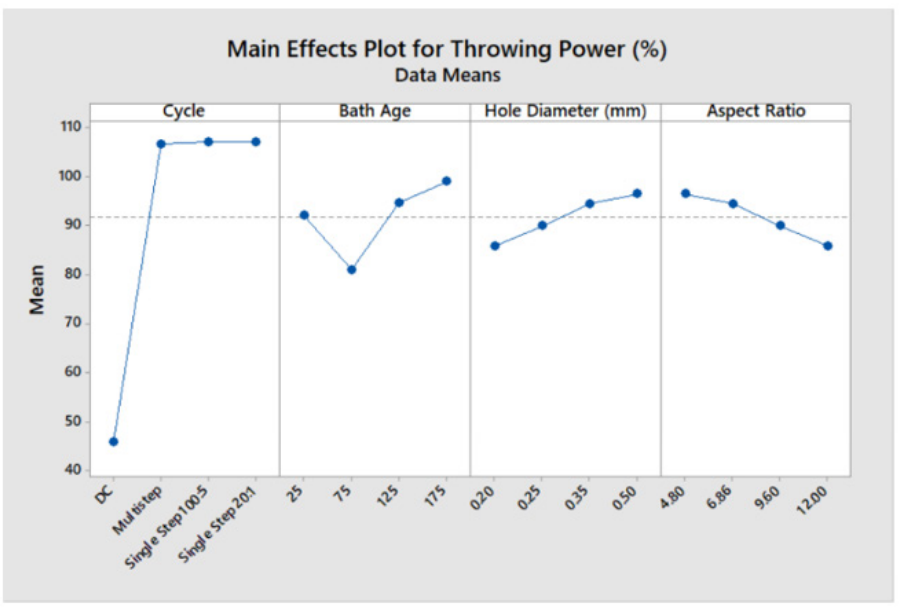

Figure 12. Minitab Main Effects Plot for $2.4 \mathrm{~mm}$ Panels

The main effect for appearance was the cycle used. The DC plated panels showed the highest rated surface: mirror bright with no burning. The multi-step pulse cycle showed a slightly less shiny appearance. The single step pulse cycles tested showed a more 
matte appearance with greater dullness in high current density areas. This is typical of pulse plated deposits. There were no significant interactions between the main conditions for both the $1.6 \mathrm{~mm}$ and $2.4 \mathrm{~mm}$ thick panels

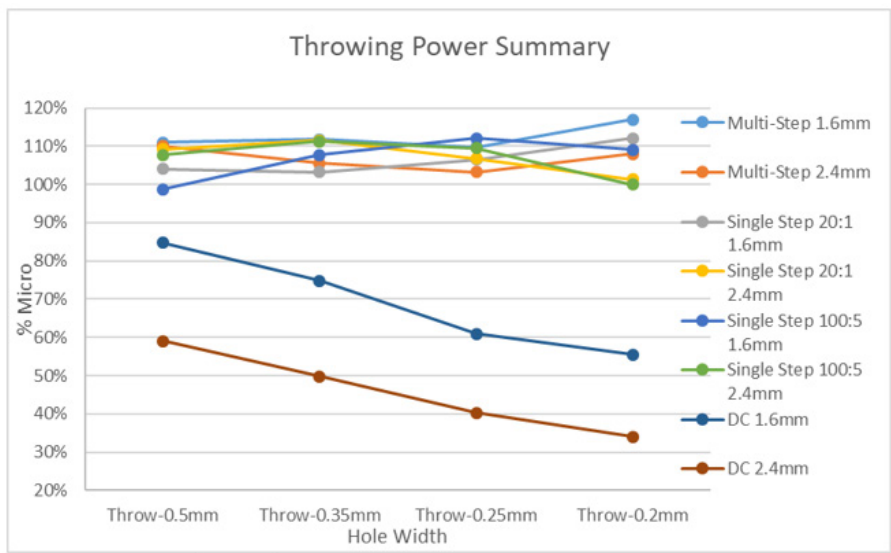

Figure 13. Throwing Power Summary

The throwing power summary graph (Figure 13) shows a comparison between all the cycles at each of the 4-hole sizes for $1.6 \mathrm{~mm}$ and $2.4 \mathrm{~mm}$ panels. The DC results were much poorer than the mid-aspect ratio pulse results. The two DC results showed a rapid deterioration in throwing power as the hole gets smaller and the aspect ratio increases. The pulse results were consistent across all the pulse waves and hole sizes, easily meeting the desired 100\% throwing power requirement.

\section{Reliability- Solder Shock}

Panels plated in the standard DC bath and pulse bath were checked for reliability with multiple tests, including a six-time solder shock at $288^{\circ} \mathrm{C}$ for 10 seconds, five-time simulated IR reflow, and tensile and elongation testing. Solder shock results showed no cracks or severe hole wall pull away for any of the cycles tested.

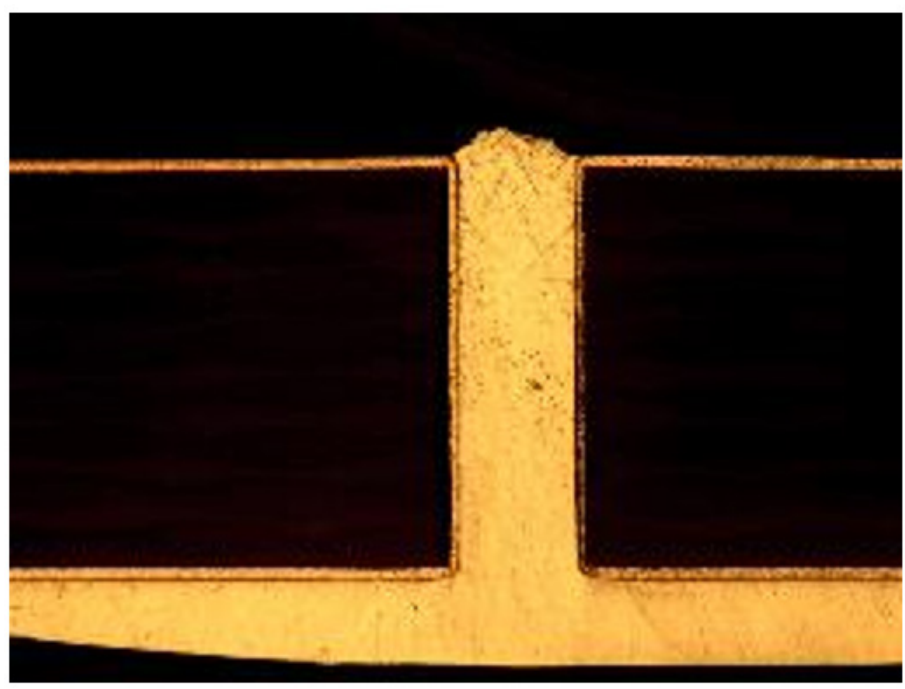

Figure 14. 6x Solder Shock at 50x magnification

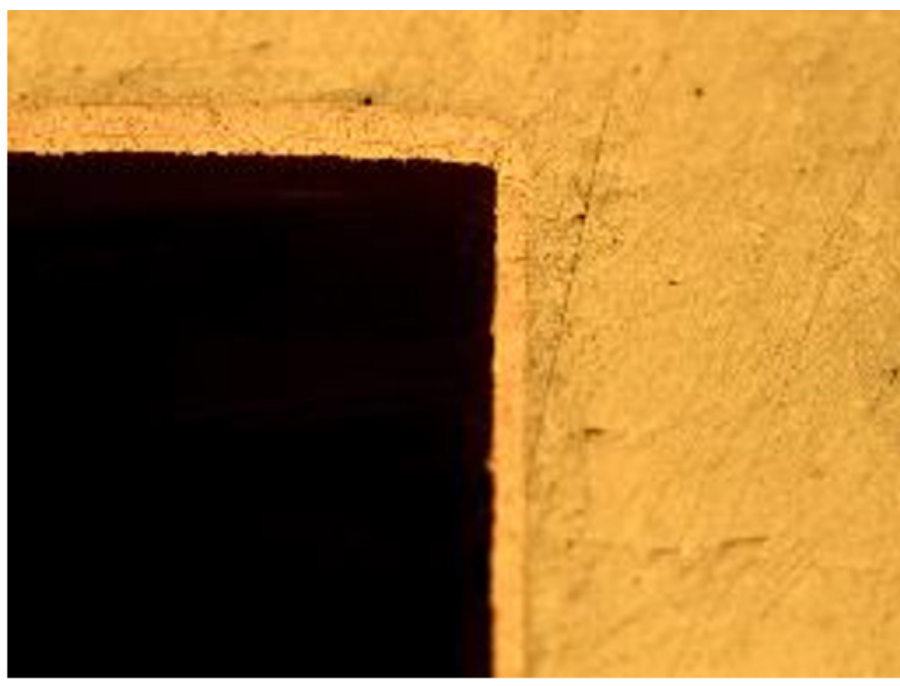

Figure 15. 6x Solder Shock at 200x magnification

The two images above (Figures 14 and 15) show typical examples of solder shocked panels. There was no difference between the DC plated and pulse plated coupons. All coupons were checked at three and six times. Each coupon was laid flat atop solder at $288^{\circ} \mathrm{C}$ for 10 seconds per exposure time. Between exposures, the coupons were cooled down and then dipped in flux.

\section{Reliability- Tensile and Elongation}

For each DC and pulse cycle tested, a stainless-steel panel was plated with 3 mils $(75 \mu \mathrm{m})$ of copper as the bath aged. The panels were plated at $25 \mathrm{Ah} / \mathrm{L}, 75 \mathrm{Ah} / \mathrm{L}, 125 \mathrm{Ah} / \mathrm{L}$, and $175 \mathrm{Ah} / \mathrm{L}$. After plating, each foil was cut into 10 strips of 5 " by $1 / 2$ " and baked at $125^{\circ} \mathrm{C}$ for 4 hours. After baking the samples were cooled and weighed. All testing for tensile and elongation were done on an Instron pull tester.

At each bath age, the four plating cycles were compared. The tensile strength remained over 30,000 PSI at all test points with a maximum of 45,000 PSI. The DC plating and multi-step cycles were slightly higher that the single step cycles (Figure 16).

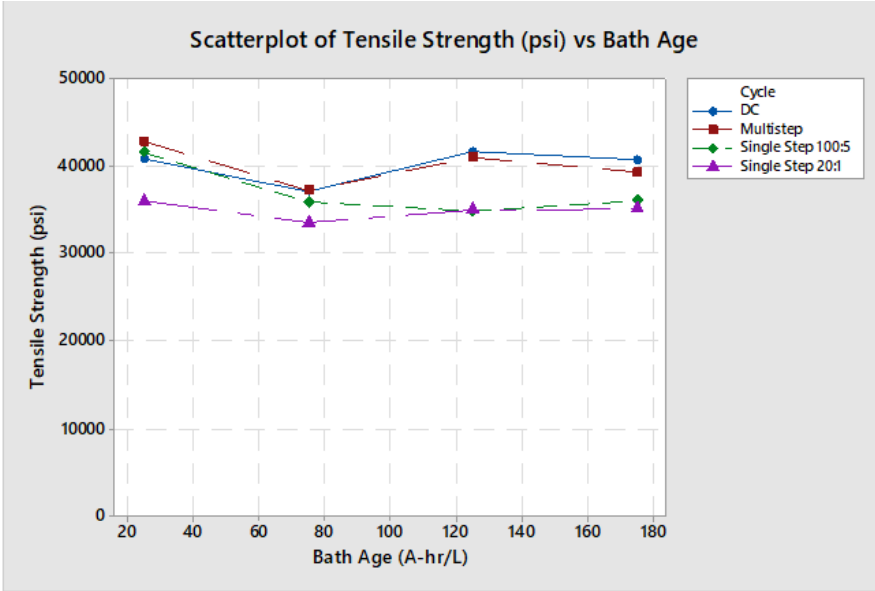

Figure 16. Tensile strength of various cycles compared to bath age 


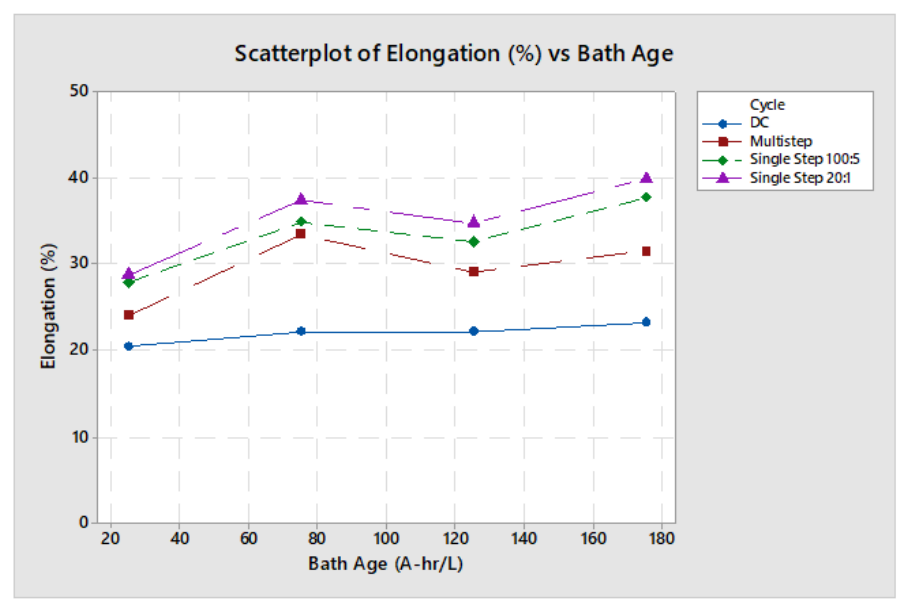

Figure 17. Elongation of various cycles compared to bath age

Elongation was also checked at each age point and showed results of $20 \%$ or greater. The elongation of pulse plated copper was consistently $10-20 \%$ greater than DC plating. The elongation climbed slightly as the bath aged and the single step 20:1 ms pulse was always the highest.

\section{Reliability-Reflow}

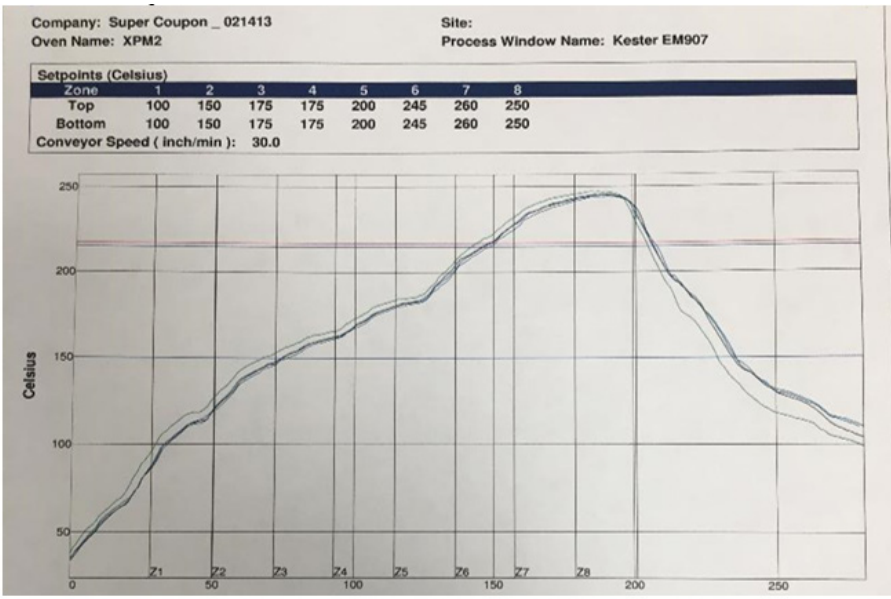

Figure 18. Simulated IR Reflow Cycle
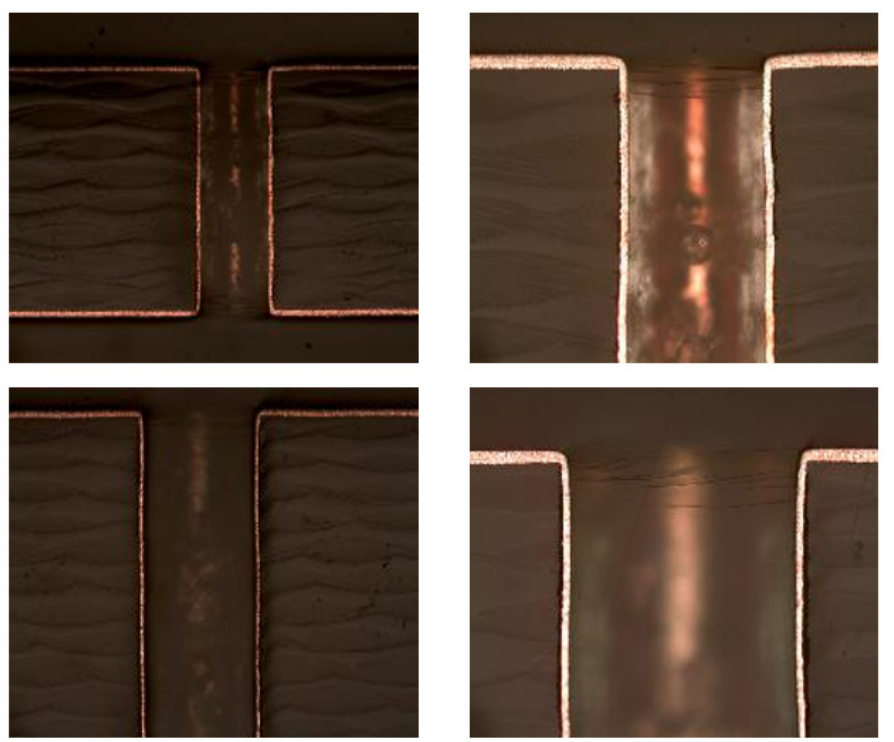

Figure 19. Cross Section photos of $5 x$ IR reflow simulation

Panels were plated at various bath ages from 5Ah/L to 200Ah/L and cross sectioned to evaluate holes and microvias for separations and cracks after reflow simulation. There were no severe cracks or separations found with any of the cycles tested.

\section{DISCUSSION \\ Consistency}

Pulse plating offers a significant advantage over DC plating due to its ability to throw deep within a through hole while easily maintaining a 1:1 ratio of copper thickness within the hole and on the surface. This technique has potential use in high volume midaspect ratio applications where meeting the minimum thickness requirements within a hole without over plating the surface can result in significant copper savings and improved throughput. The savings obtained by these improvements can easily offset the higher cost of a pulse rectifier.

\section{Cost Savings}

As an example, assuming the values outlined in Table 2, a DC bath with $70 \%$ throwing power will need to plate an additional 10.9um of copper on the surface to meet the minimum 25.4um thickness requirements in the hole.

Table 2. Cost Saving Assumptions and Calculation

\begin{tabular}{|c|c|c|c|c|c|}
\hline \multicolumn{2}{|l|}{ DC Bath } & \multicolumn{2}{|c|}{$70 \%$} & Panels/day & 1000 \\
\hline \multicolumn{2}{|l|}{ PPR } & \multicolumn{2}{|c|}{$100 \%$} & Plating days/yr & 250 \\
\hline \multicolumn{2}{|c|}{ Exposed Area } & \multicolumn{2}{|c|}{$50 \%$} & Copper anodes & $\$ 3.00 / \mathrm{lb}$ \\
\hline \multicolumn{2}{|c|}{$\begin{array}{l}\text { Wt of Cu/um/panel } \\
(18 \times 24)\end{array}$} & \multicolumn{2}{|c|}{$4.97 \mathrm{~g}$} & A-min/25.4um & 1200 \\
\hline $\begin{array}{l}\text { Throwing } \\
\text { Power } \\
\text { (\%) }\end{array}$ & $\begin{array}{l}\text { Hole Wall } \\
\text { Thickness } \\
\text { (um) }\end{array}$ & $\begin{array}{c}\text { Required } \\
\text { Surface } \\
\text { Cu } \\
\text { (um) }\end{array}$ & $\begin{array}{c}\text { Additional } \\
\text { Cu } \\
(u m)\end{array}$ & $\begin{array}{l}\text { Additional } \\
\text { Cu Anodes }\end{array}$ & $\begin{array}{l}\text { Savings } \\
\text { (USD) }\end{array}$ \\
\hline $100 \%$ & \multirow{2}{*}{25.4} & 25.4 & \multirow{2}{*}{10.9} & \multirow{2}{*}{$6772 \mathrm{~kg}(14,898 \mathrm{lbs})$} & \multirow{2}{*}{$\$ 44,692$} \\
\hline $70 \%$ & & 36.3 & & & \\
\hline
\end{tabular}


This translates to a savings of approximately 15,000lbs of copper anodes per year in addition to the cost of not having to strip that amount of copper and treat the generated waste.

In addition to the savings in copper usage and treatment, there is also a throughput increase. Under the assumptions above in Table 2, the additional copper plated to meet the thickness requirement in the hole requires 17 minutes of additional plating time over the 40 minutes required to plate at 100\% throwing power. This represents an additional 11 loads per day, or a potential increase in throughput of approximately $43 \%$.

Table 3. Increased Throughput Calculation

\begin{tabular}{|c|c|c|c|c|c|}
\hline Bath & $\begin{array}{l}\text { TP } \\
(\%)\end{array}$ & $\begin{array}{l}\text { Cu Thick } \\
\text { in Hole } \\
\text { (um) }\end{array}$ & $\begin{array}{l}\text { Surface Cu } \\
\text { Required } \\
\text { (um) }\end{array}$ & $\begin{array}{l}\text { Cycle Time } \\
\text { @30ASF } \\
\text { (min) }\end{array}$ & $\begin{array}{c}\text { Loads per } \\
\text { Day } \\
(24 \mathrm{hr})\end{array}$ \\
\hline DC & 70 & \multirow{2}{*}{25.4} & 36.3 & 57.1 & 25.2 \\
\hline PPR & 100 & & 25.4 & 40 & 36 \\
\hline \multicolumn{3}{|c|}{ Increased Throughput } & \multicolumn{3}{|c|}{$42.9 \%$} \\
\hline
\end{tabular}

\section{CONCLUSION}

As electronics continue to evolve, and board architecture changes to accommodate new designs, the use of pulse plating for mid-aspect ratio PCBs to maintain production throughput can be a viable option to conventional high throw DC plating.

Pulse plating can plate a copper deposit with excellent physical properties deep into a through hole with 100\% throwing power at relatively high current densities, allowing a fabricator to maintain high throughput, minimize copper usage, and reduce etching and waste treatment volumes. Though rectifier costs are still higher for pulse plating than DC plating, costs have come down significantly and can be further offset due to the process savings of pulse plating. Considering the drawbacks of DC plating in terms of speed and thickness distribution, pulse plating can be a viable economical solution for high volume plating of thicker mid-aspect ratio products.

\section{ACKNOWLEDGEMENTS}

The authors would like to thank the various technical centers from MacDermid Alpha Electronic Solutions that did some of the testing and data collection. In addition, a special thank you to George Viola and American Plating Power for providing quotes and additional information about pulse and DC rectifiers.

\section{REFERENCES}

[1] N. Osero, "An Overview of Pulse Plating", Plating and Surface Finishing March 1986 pp. 20-22

[2] R. Bellemare, C. Gugliotti, "The Effect of Board Design on Electroplated Copper Filled Thermal Vias For Heat Management", Proceedings of SMTA International March 2017

[3] M. Nikolova, J. Watkowski, "Innovative High Throw Copper Electroplating Process for Metallization Of PCB", Proceedings of Pan Pacific Symposium January 2011

\section{BIOGRAPHIES}

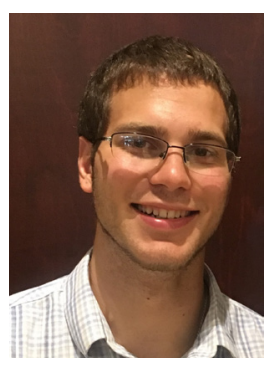

Carmichael Gugliotti is a Metallization Applications Manager at MacDermid Alpha Electronic Solutions based in Waterbury, CT. He holds a Bachelor's of Science in Chemistry from the University of Connecticut. He has worked on new metallization technologies for acid copper plating with a focus on via fill, high throw DC copper, and pulse plating. 